\section{DANDELION}

postgraduate arts journal \& research network

VOLUME 8 NUMBER I SUMMER 2017

\section{SARAwUt ChutiwongPeti}

is an artist who lives and works in various places around the world. His film works and installations are highly personal; a means to make connections between his native country, Thailand, and its culture, and the living aesthetics of a neo-nomadic artist.

www.chutiwongpeti.info

\title{
Short Circuit
}

\section{The Neo-Nomadic Artist}

\author{
Sarawut Chutiwongpeti
}

Sarawut Chutiwongpeti's ARTWORK FOCUSES ON ISSUES RELATED TO CULTURAL TRANSFORMATION, GLOBAL MOBILITY AND THE PRECARIOUS SITUATION OF THE NEO-NOMADIC ARTIST. Everyday aesthetics play an important role in his installations where he works with consumer packaging, mainly from food products, to represent how things and people from around the world converge in a single location.

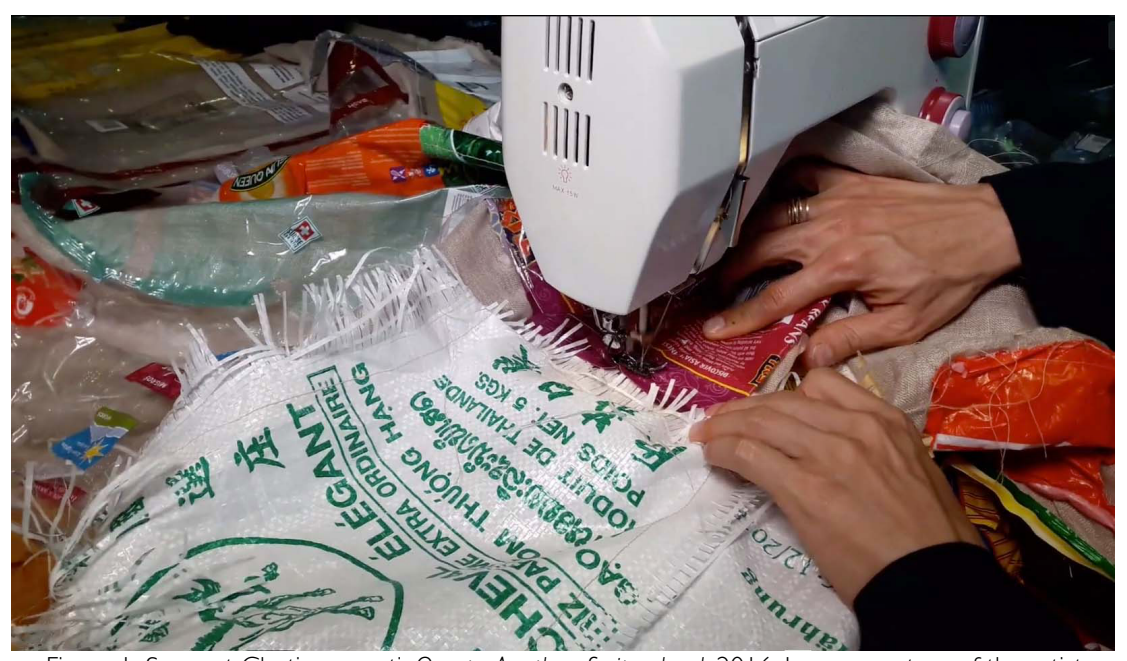

Figure I. Sarawut Chutiwongpeti, One to Another, Switzerland, 2016. Image courtesy of the artist 


\section{Sarawut Chutiwongpeti interviewed by Donatella Valente}

Donatella Valente: Can you elaborate on the notions of 'neo-nomadic artist' and 'living aesthetics'?

Sarawut Chutiwongpeti: When I was first called 'neo-nomadic' I felt embarrassed, I did not really like the term. It seemed to suggest I was floating on a river with no direction.

But indeed, I am a 'neo-normadic artist'. For me, this means when someone has made the decision to find the best quality of life in the greatest place. I could go back to my country at any time. My family always waits and hopes I will go back home to stay permanently. I know well how sad and painful it must be, that it hurts to be away from the ones you love. On the other hand, I am happy to see the world and gain value from my experiences. But I always miss my family and worry about them as my parents are aging. This makes me reflect about how to find a balance in life between happiness and sadness. There are always two opposite aspects to reconcile; no one can experience just one.

Beside fate and fortune, I put a lot of effort into making things happen. Being either nominated or awarded fellowships allowed me to live or stay temporarily in many places. I have also been occasionally invited. It is not the same as being a backpacker, organising everything and travelling on my own.

'Living aesthetics' does not mean a life lived in luxury, or a comfortable lifestyle; it is about the way things are. How could I enjoy my life on any ordinary day, on a 'grey' day? Or how do I learn to live with any situation, even in difficult times? I have become aware that life must go on.

Lately, I have found that the 'reality' of life is very charming, and this is one of the keys to the 'grammar of things'.

Q.: Film documentation of One to Another (2016), a site-specific installation and performance, shows you emptying many carrier bags of their content, food wrappings and packaging, before laying the discarded material across the floor of your studio.

It could be argued that this documentary conveys the intensified, relational aesthetics of life experience. While punctuated by rituals, rhythms, and repetitions, its ostensibly mechanically assembled sets of movements are fluidly patterned. The documentary demands aesthetic attention for, as the title One to Another articulates, it foretells intention from both One subjectivity to Another, and movement from One place to Another. Its open semantic relation invokes thinking about separation and evanescence. Thus, through this 'grammar of things', as you mention, the relational aesthetics of life experience in One to Another could be read as being about inter-subjectivity and intraspatiality.

In Aesthetics of Everyday Life: East and West, Liu Yuedi and Curtis L. Carter argue that the interior structure of everyday life aesthetics is complex, taking place on two levels: one is on the surface, and the other at depth. While the former refers to the superficial aesthetic transformation of material living, the latter goes deeper into the aesthetic experience of inner worlds. ${ }^{1}$ Although your exhibition of empty plastic containers in One to Another is ostensibly organised according to aesthetically engaging patterns, it also conveys the depth of your experience of the everyday. The presentation of waste packaging discourages any passive engagement with the surface layers of these consumer 
products, sourced in a variety of places yet rooted in specific cultural traditions. worlds'?

How does this documentary evoke the aesthetic experience of 'inner

Once, after a long wait at the airport, as the Customs officers were checking my documents, I wondered how the world would be if, even for one day only, it had no borders! But once I am in a different country, I become used to being part of a different society and realise that ordinary life is organized according to repetitive patterns forming a series of loops of actions and behaviours: for example, waiting for a bus, trying to catch a train, eating and sleeping, etc.

I always try to organize my life as a system. I like to go to sleep early and wake up early, and eat on time. I cook the same menu of vegetarian meals almost every day; a routine I do not always enjoy. You may imagine the point of view of a free artist who is fluid like water. But I try to organise my life in a similar fashion to how many people shape theirs.

One to Another is the first piece I performed in public. I rarely show myself on video and only occasionally perform in public. Based on lived aesthetics during my stay in Switzerland, shopping in Emmen for the ingredients to prepare traditional Thai meals, the work aims to represent an array of experiences of different temporalities and consumerism.

I am always on the move, from one country to another. At times, my perceptions of the outer and inner world are confused, blurring fantasy with reality. After so many years of regular travelling, my mind now sees the world as 'no country'. It is quite another perception now than when I first travelled to Japan in 1999. On that occasion, everything was new to me. My heart started beating fast when my airplane landed in Tokyo, and I was very excited about the novelty of the environment. But now, perhaps because I have been travelling quite regularly, my perceptions of the uncommon have become familiar and part of the ordinary environment.

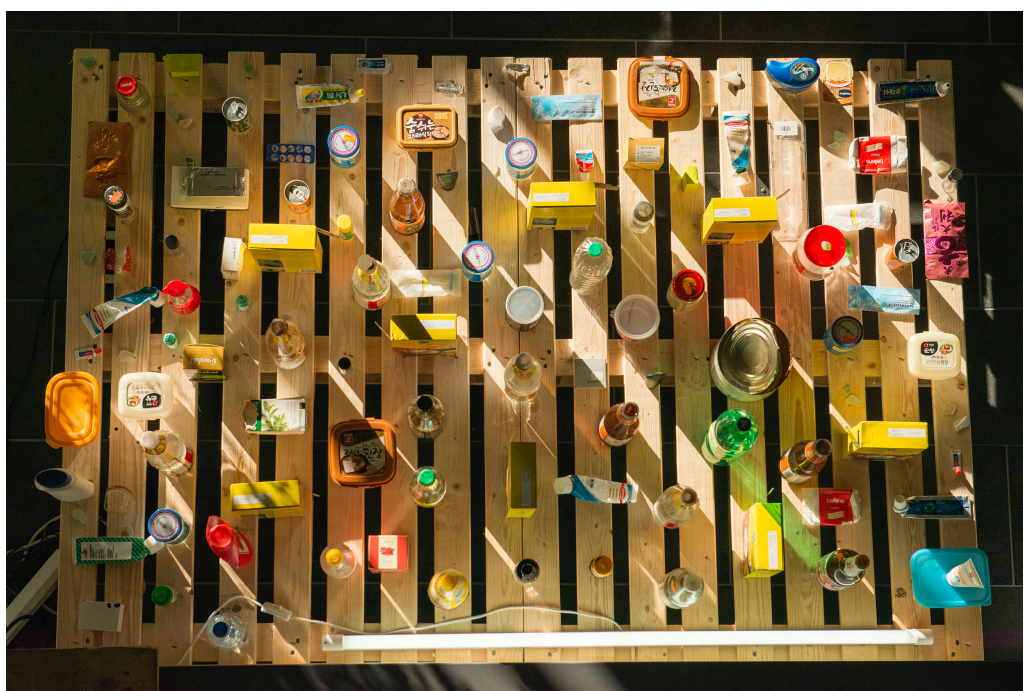

Figure 2. Sarawut Chutiwongpeti, Untitled (Wishes, Lies and Dreams), 2016. Installation image courtesy of the artist

Q.: The video Wishes, Lies and Dreams $>>$ The Dream of Greater Countries (2016) from the installation series Wishes, Lies and Dreams (2000-present), centres around the experience of difference. It could be read as an oneiric fable on multiculturalism. Its evocative imagery and dreamscape share an aesthetic sensibility, the same range of hues and tones, specific to the saturated greens of natural landscapes, and is reminiscent of another poetic film and video artist 
from Thailand working with fantastic imagery and folkloric tales, Apichatpong Weerasethakul. On the other hand, many of these images are not from any particular country, rather they engage organically with the aesthetics of natural environments, which generate social consciousness founded on human relations and shared living aesthetics. Does this installation series change every year to include new experiences of your living in different countries?

I began working on the Wishes, Lies and Dreams $>>$ series in 2000 when I was artist in residence at the Banff Center for Arts and Creativity in Canada, and discovered by chance the atmosphere that would allow me to create the piece, although at first, I made plans for a lighting installation. For me, both the environment and the atmosphere were so wonderfully congenial to my creativity. After finishing the residency program in Canada, I went to New York, then to Denmark and the surrounding Northern European countries. I am still continuing this project in different locations and countries all over the world.

The video Wishes, Lies and Dreams >> The Dream of Greater Countries that you have watched says something about my character, my positivity and solitude: this is how I see the world. At times, when travelling from one side of the world to another, I can spend almost forty-eight hours on the road, perhaps longer, without sleeping. After I reach my destination and go to bed, I sometimes become confused and start wondering where I currently am.

Q.: In contrast to the documentary From One to Another, the pattern of discrete images that form the video installation Wishes, Lies and Dreams $>>$ The Dream of Greater Countries unravels rather fluently to evoke contemplation. Your spiritual journey, as you put it, is about learning and discovery, about the future, which also, to you, means Utopia. It seems to map a constellation of dream-like possibilities, or nocturnal visions. I'm interested, however, to know how your wishes are represented figuratively in this video?

Is its lyrical narrative an expression of your cultural ease as a 'neonomadic artist' having become used to cultural diversity? If so, how do these transformative experiences inspire both the physical and spiritual space that you inhabit?

During my stay in Switzerland, I was fascinated by the unexpected situations I experienced. This state of mind makes me open-up and turn away from my fantasy worlds and wishful thinking, and face reality: the opposite of travelling. I am very interested in the idea of an imperfect world and the fragility of life. I am 'A Dreamer'. I have, in the past, felt disconnected and refused to get involved with politics and society. But the 'beautiful thinking' has stopped. I have felt disappointed in many situations, and as a contemporary artist I feel I have a responsibility to interact with society.

In the fall of 2015, I was invited to create a new art installation at Sea Art Festival, Busan Biennale in South Korea. I titled my works Beautiful New World. On my way back to Switzerland, I encountered some difficulties while travelling and now I cannot see the world as quite so welcoming, as I once did. I met many refugees and immigrants with whom I became friends. I listened to their stories, with which I sympathised. Ultimately, I was allowed to stay in Switzerland. I still remember very well my friends' sadness as they were not allowed to stay. They had to go back to their own country.

After other similar disappointments, I looked at the world differently, and realised I would like to start interacting with everyday real life and society. This attitude became the starting point and means for me to combine the art of real life with factual stories on the human condition. Besides cultivating my inclination for beauty, wishes, and dreams, my daily life now also involves social interaction. 


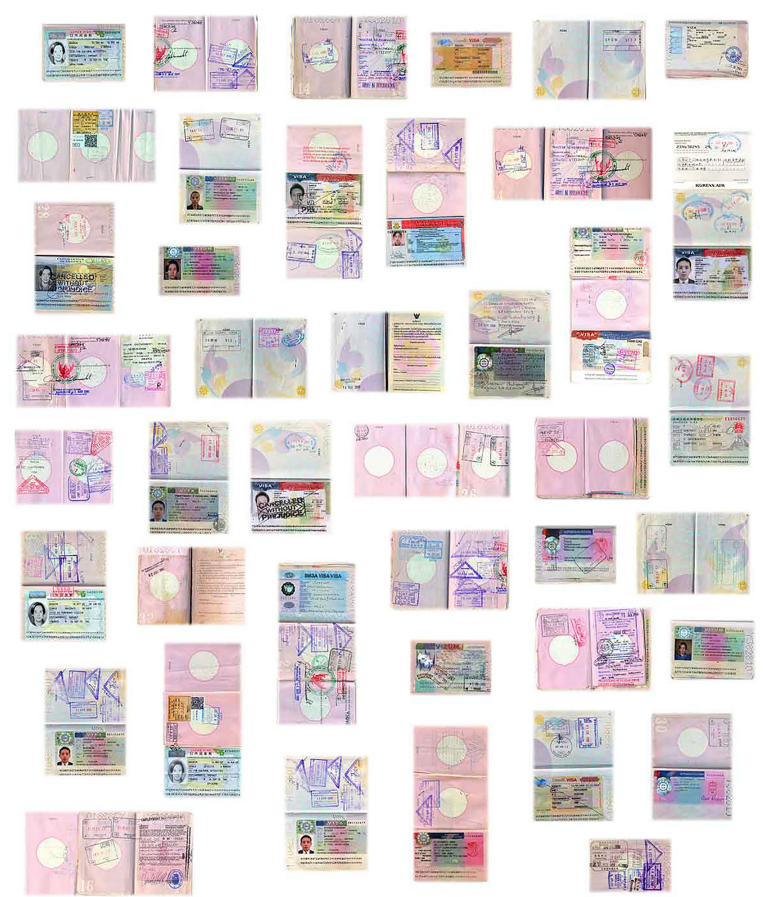

Figure 3. Sarawut Chutiwongpeti, One to Another, Switzerland, 2016. Image courtesy of the artist

Q.: Which artist and artworks have inspired you most?

Those who inspire me most and have influenced me are my family who are so close to me and with me all the time. My parents are my greatest sources of inspiration; they keep me motivated and encourage me to hold my head high and keep moving.

Regarding artists, I rate highly the great creative personalities of Marcel Duchamp and Joseph Beuys. However, my admiration for them does not originate from any book or curator's catalogue, theorist or art historian. Rather, it stems from my real feelings for their artwork, as I experience it personally.

Q.: How have your experiences of exhibiting in public, and in a variety of countries, contributed to seeing yourself as a neo-nomadic artist?

I see my places of destination as if I were visiting 'Utopia Station' at each stop. ${ }^{2}$ Each has its own spirit, message and character. I always start from point Zero, approaching new landscapes and environments with a naïve attitude and vague ideas, which I later explore to let them reveal new meanings. From this I draw inspiration and discover clarity in my ideas which become aesthetic experiences, transformed into art. Many come to me suddenly while I am travelling and experiencing unfamiliar situations. These are the key aesthetic experiences that inspire my art installations.

As I search for primary materials that I can transform into art, I appreciate the value of the exotic, ethnic culture of my world. The more I travel to the West, the more I look to the East and the route of my life as an artist.

\section{Q.: What future projects do you have planned?}

I have started collecting found objects. My current idea for my next art project is to use industrial sites combined with performance, but this will depend on any 
restrictions I encounter.

Currently, I am in Ulsan, South Korea. The place where I am staying is surrounded by a large industrial complex, and my studio/living space is close to the Sea Port. At night, sounds from the ships disrupt my tranquillity. I then start having several ideas about how to realise a new project, which I initially approach with a sense of wonder and without any sense of concreteness.

I had planned to shoot a video inside a car manufacturing plant and the largest energy/oil company in South Korea, but as I was only allowed to take a tour inside the building when they were not open to the public, I will attempt to fulfil this type of artwork in other countries. I have already started shooting a video outside the building in the industrial compound. While I am very interested in architecture, I have never seen or lived in such a large business environment as this one in my whole life! The urban and industrial landscapes look like an imaginary new world on Mars.

Another idea I have is to apply for a job to experience the labour conditions of the working-class and refugees. It seems that my future direction will be about time and history.

\section{Notes}

1 Yuedi, Liu and Curtis L., Carter, Aesthetics of Everyday Life: East and West (Cambridge: Cambridge Scholars Publishing, 2014), p. x.

'Utopia Station' was a project space at the $50^{\text {th }}$ Venice Biennale, $15^{\text {th }}$ June $-2^{\text {nd }}$ November 2003, curated by Molly Nesbit, Hans-Ulrich Obrist and Rirkrit Tiravanija. 